resinas bis-acrílicas. Materiais e métodos: Utilizando um molde de aço inoxidável, foram fabricados 420 espécimes. Os 210 espécimes de cada resina (Protemp 4; Structur 3) foram divididos aleatoriamente em 28 grupos $(n=15)$. Para cada material, foram criados 2 grupos controlo sem qualquer tratamento térmico, em que os testes de resistência à flexão foram realizados num grupo aos 30 minutos após o início da mistura do bis-acrílico e no outro às 24 horas. Os 24 grupos experimentais foram constituídos de acordo com as diversas combinações entre resina bis-acrílica, tipo (micro-ondas, banho de água a $60 .{ }^{\circ} \mathrm{C}$, e secador) e duração do tratamento térmico (1, 2, 3, e 4 minutos). Os testes de resistência à flexão com 3 pontos (distância entre hastes $20 \mathrm{~mm}$; velocidade de deslocamento $0,75 \mathrm{~mm} / \mathrm{min}$ ) nos 24 grupos experimentais foi realizada 30 minutos após o início da mistura do bis-acrílico. A análise estatística foi efetuada com testes Mann-Whitney, Kruskal-Wallis e ANOVA $(\alpha=0,05)$. Resultados: O Protemp 4 apresentou uma resistência à flexão estatisticamente $(p<0,001)$ mais elevada do que o Structur 3. Foram observadas diferenças estatisticamente significativas $(p<0,001)$ entre os 3 tipos de tratamento térmico, tendo o microondas permitido obter os valores mais elevados. Quanto à duração do tratamento térmico, o condicionamento dos espécimes durante 2 minutos permitiu obter valores de resistência significativamente $(p=0,001)$ mais elevados que o tratamento durante 1 minuto, mas não se observaram diferenças estatisticamente significativas ( $p>0,05)$ entre os 2, 3 e 4 minutos. Em todos os grupos experimentais verificaram-se valores de resistência à flexão estatisticamente $(p<0,001)$ mais elevados do que os obtidos no respetivo grupo controlo com 30 minutos de envelhecimento. Com exceção do banho de água durante 1 e 2 minutos e do secador durante 1 minuto para os espécimes fabricados com Structur 3, todos os tratamentos térmicos realizados permitiram obter resistência à flexão estatisticamente semelhante ou superior à verificada no grupo controlo com 24 horas de envelhecimento. Conclusões: O tratamento térmico pós-polimerização com microondas permitiu obter valores de resistência à flexão mais elevados que os restantes métodos. O tratamento térmico deverá ser realizado durante 2 minutos, com exceção do banho de água para Structur 3 que deverá ser realizado durante 3 minutos. http://doi.org/10.24873/j.rpemd.2020.12.802

\section{\#080 Efeito da duração de tratamento térmico na microdureza de resinas bis-acrílicas}

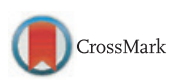

Margarida Venâncio*, Sara Brás Gomes, Bruno Seabra, Filipa Chasqueira, Jaime Portugal

Faculdade de Medicina Dentária da Universidade de Lisboa

Objetivos: Avaliar a influência do tipo e do tempo de tratamento térmico pós-polimerização na microdureza de duas resinas bis acrílicas. Materiais e métodos: Com auxílio de um molde metálico foram confecionados 210 espécimes para cada resina bis-acrílica estudada (Protemp 4 e Structur 3) e divididos em 28 grupos ( $n=15)$. Foram constituídos 24 grupos experimentais de acordo com as combinações possíveis entre resina bis-acrílica, tratamento térmico pós-polimerização (banho de água a $60^{\circ} \mathrm{C}$; secador de cabelo; micro-ondas) e duração do tratamento térmico (1, 2, 3 e 4 minutos). Para cada resina, foram constituídos 2 grupos de controlo sem tratamento térmico, de acordo com o período de envelhecimento que decorreu entre o início da mistura do bis-acrílico e o teste de microdureza Knoop (30 min. e 24 h). Para os grupos experimentais, foi determinada a microdureza $(98,07$ $\mathrm{mN}, 20 \mathrm{seg}$ ) 30 minutos após o início da mistura do bis-acrílico. Os dados obtidos foram analisados com testes não paramétricos de Mann Whitney U e Khruskal Wallis $(\alpha=0,05)$. Resultados: De uma maneira geral, o Protemp 4 apresentou microdureza estatisticamente $(p<0,001)$ mais elevada que $o$ Structur 3. Relativamente aos tratamentos térmicos, o banho de água a $60^{\circ} \mathrm{C}$ permitiu obter microdureza estatisticamente $(p<0,001)$ mais elevada que os restantes tratamento térmicos, e não se observaram diferenças estatisticamente significativas $(p=1,000)$ entre a microdureza dos espécimes submetidos ao calor do secador de cabelo e dos espécimes condicionados com micro-ondas. Ainda de uma forma geral, não foi possível observar uma influência estatisticamente significativa $(p=0,171)$ do tempo de tratamento sobre a microdureza. Comparando os grupos experimentais com os grupos controlo, a maioria dos tratamentos térmicos permitiu obter um aumento estatisticamente significativo da microdureza à observada aos 30 minutos sem tratamento $(p<0,05)$. Todos os métodos de tratamento térmico (tempo e tipo) permitiram obter uma microdureza estatisticamente semelhante $(\mathrm{p}>0,05)$ à observada às 24 horas sem tratamento, tendo em alguns casos, sido possível obter valores de microdureza estatisticamente $(\mathrm{p}<0,05)$ mais elevados que este grupo controlo. Conclusões: Os valores de microdureza não foram influenciados pelo tempo de tratamento térmico pós-polimerização e todos os métodos de tratamento estudados permitiram obter valores de microdureza semelhante ao observado no grupo de controlo ao fim de 24 horas de polimerização.

http://doi.org/10.24873/j.rpemd.2020.12.803

\section{\#081 Influência de inibidores de Metaloproteinases na resistência adesiva à dentina CrossMark}

Inês Carpinteiro*, Helena Laronha, Jorge Caldeira, Ana Mano Azul, Jaime Portugal

Faculdade de Medicina Dentária da Universidade de Lisboa; Centro de Investigação Interdisciplinar Egas Moniz Instituto Universitário Egas Moniz

Objetivos: Testar o efeito de inibidores de metaloproteinases na resistência adesiva à dentina de um adesivo etch-and-rinse, ao longo de 6 meses. Materiais e métodos: Trinta molares humanos hígidos foram distribuídos aleatoriamente em seis grupos experimentais $(n=5)$ de acordo com o inibidor utilizado: OPT FL (sistema adesivo etch-and-rinse de 3 passos Optibond FL sem inibidor); CHX 0,2 (Optibond FL CHX 0,2\%); CHX 2 (Optibond FL CHX 2\%); IE1 (Optibond FL inibidor experimental 1); IE2 (Optibond FL inibidor experimental 2); IE3 (Optibond FL inibidor experimental 3). Após a polimerização do sistema adesivo, foi sobre ele aplicado o compósito microhí- 